\title{
Liselerdeki Fen Eğitiminde Teknolojinin Kullanılmasına Yönelik Öğrenci Görüşlerinin Çeşitli Demografik Faktörler Açısından İncelenmesi***
}

\section{Pelin DEVRAN*, Enes Abdurrahman BÍLGíN**}

Öz: $\mathrm{Bu}$ çalışmada, ortaöğretim öğrencilerinin, liselerdeki fen eğitiminde teknolojinin kullanılmasına yönelik görüşlerinin belirlenmesi amaçlanmıştır. Ayrıca öğrencilerin tercihlerine cinsiyet, okul türü, sınıf düzeyi, öğrenim görülen kurum ve ölçeğin yanıtlandığı ders faktörlerinin etkilerinin açığa çıkartılması amaçlanmıştır. Çalışmanın yöntemi nicel araştırma yöntemlerinden ilişkisel tarama modeli olarak belirlenmiştir. Çalışmanın örneklemini 2020-2021 eğitim öğretim güz yarıyılında Doğu Anadolu Bölgesindeki farklı illerinde öğrenim görmekte olan 199 ortaöğretim öğrencisi oluşturmaktadır. Araştırmanın verilerine ulaşmak amacıyla Erdem ve Uzal (2018) tarafından geliştirilen ve tüm fen bilimleri için geçerli olan “Teknolojinin Fizik Eğitiminde Kullanımına Yönelik Öğrenci Görüş Ölçeği” kullanılmış ve toplanan veriler SPSS 18 paket programında analiz edilmiştir. Analiz sürecinde betimsel ve yordamalı istatistik teknikleri kullanılmıştır. Yapılan analizler sonucunda, öğrencilerin teknolojinin fen derslerinde kullanımına yönelik \%78 oranında olumlu görüş belirttiği sonucuna ulaşılmıştır. Ayrıca ortaöğretim öğrencilerinin liselerdeki fen eğitiminde teknolojinin kullanımına yönelik görüşlerinin cinsiyet, sınıf düzeyi, okul türü, öğrenim görülen kurum ve ölçeğin yanıtlandığı fen dersine göre değişiklik göstermediği tespit edilmiştir.

Anahtar Kelimeler: Fen, Teknoloji Kullanımı, Lise, Öğrenci Görüşleri

\footnotetext{
*Yüksek Lisans Öğrencisi, Van Yüzüncü Y1l Üniversitesi Eğitim Bilimleri Enstitüsü, Email: pelindvrn.1@gmail.com, Orcid No: 0000-0003-1834-2781

**Dr. Öğr. Üyesi, Van Yüzüncü Y1l Üniversitesi, Eğitim Fakültesi, Email: enesbilgin@yyu.edu.tr, Orcid No: 0000-00033003-9259

${ }^{* * *} \mathrm{Bu}$ araştırma için Van Yüzüncü Yıl Üniversitesi Sosyal ve Beşeri Bilimleri Etik Kurulu Başkanlığında (30/12/2020 tarih ve 2020/15-08 sayıs1) etik izin alınmıştır.
}

Gönderim:25.03.2021 Kabul:15.05.2021 Yayın:30.06.2021




\section{Examination of Student Views on the Use of Technology in Science Education in High Schools in Terms of Various Demographic Factors}

Abstract: This study aimed to determine the opinions of secondary school students regarding the use of technology in high school science education. It also aimed to reveal the effects of gender, school type, grade level, the institution of education and the subject related factors on students' opinions. The correlational survey model, a quantitative research method, was used as the method of the study. 199 secondary education students studying in different provinces of the Eastern Anatolia Region in the fall semester of 2020-2021 academic year have been chosen the sample group of the study. The "Student Opinion Scale for the Use of Technology in Physics Education", which was developed by Erdem and Uzal (2018) and suitable for all science subjects, was used in order to obtain the data of the study and the collected data were analyzed by using the SPSS 18 software. In the analysis process, descriptive and inferential statistical techniques were used. According to the findings of the study, it can be concluded that the students expressed a positive opinion at a rate of $78 \%$ regarding the use of technology in science lessons. Moreover, it was found that gender, grade level, type of school, institution of education and the subject related factors had no impact on secondary school students' views on the use of technology in science education in high schools.

Keywords: Science, Use of Technology, Education, Student Opinions

\section{Giriş}

Günümüzün vazgeçilmez unsurlarından biri olan teknolojinin kaydettiği ilerleme yadsınamaz boyutlara ulaşmış ve sürekli gelişmeye devam etmektedir. Özellikle kullanıldığı alanların artması ile beraber hayatımızın hemen her alanında kendini gösteren teknoloji artık eğitim dünyasında da fazlasıyla yerini almıştır (Gökduman, 2017). Diğer taraftan eğitimde çağdaş seviyeyi yakalamanın en önemli şartı sunulan içerik olsa da bu içeriği sunmak için kullanılan araç ve yöntemler de büyük önem arz etmektedir. Bu açıdan araç ve yöntemlerin en önemlisi olarak yine teknoloji karşımıza çıkmaktadır (Bozkurt, 2014). Dolayısı ile teknoloji artık eğitimde kitaplar, öğretmenler, okullar kadar vazgeçilmez bir araç haline gelmiştir. Ayrıca teknolojideki yeni buluş ve ilerlemelerle, eğitimin planlanması, yönetilmesi, uygulanması ve değerlendirilmesi alanlarında bu teknolojik yeniliklerden nasıl yararlanılabileceği de araştırılmaktadır (Çağıltay ve Erdoğmuş, 2009).

Diğer taraftan günümüz toplumunun temel ihtiyacı bilgiyi ezberleyen bireyler yerine, bilgiye ulaşabilen, gereken durumlarda bilgiyi anlayıp kullanabilen bireylerin yetiştirilmesidir. 
$\mathrm{Bu}$ açıdan toplumun gereksinimlerinin karşılanmasına yönelik bireylere, bilgiye ulaşma yeteneği ve bilimsel yöntem ve süreç becerilerinin kazandırılması gerekmektedir. $\mathrm{Bu}$ kazanımlara yönelik verilen derslerin başında ise tabii olarak fen dersleri gelmektedir (Korkmaz ve Kaptan, 2001). Fen derslerinin öğretiminde ise öğrencilerin canlıları, fiziksel ve kimyasal olayları, hayatın biyolojik temellerini, deneye dayalı öğrenme vb. yöntemler ile öğrenmemesi durumunda biyoloji, kimya ve fizik dersleri doğal olarak ezber yapılması gereken dersler olarak algılanmaktadır (Çakmak, 1999). Özellikle öğrencilerin fen derslerinde soyut kavramları öğrenmekte zorlandıkları ve bu kavramları somutlaştırarak derinlemesine öğrenemedikleri bilinmektedir (Akpınar, Aktamış ve Ergin, 2005). Dolayısı ile Fen derslerinde hedeflenen bireylerin yetiştirilmesi ve belirtilen problemlerin çözümü açısından fen eğitiminde teknolojinin kullanımı önemli hale gelmiştir. Bu açıdan teknolojinin fen eğitiminde kullanımı, öncelikle zihinde canlandırılması zor olan soyut konuların somutlaştırılmasında, ders ortamında ulaşılması zor veya imkânsız alanların sanal olarak kullanılmasında fayda sağlamaktadır. Yine öğrencinin öğrenme hızına uyum sağlanmasında, öğretimin eğlenceli ve kalıcı kılınmasında, tehlikeli ve sınıfta yapılması mümkün olmayan deneylerin sanal ortamda gösterilmesinde büyük kolaylıklar sağladığı görülmektedir (Aykanat, Doğru ve Kalender, 2005; Demirci, 2003). Bunların yanında teknolojinin fen derslerinde kullanımı öğrencilerin Fen’e olan ilgi ve meraklarını arttırmakta ve buluşçu olmaya yönelik olumlu tutum sergileyen bireylerin yetişmesine olanak sağlayabilmektedir (Akpınar ve ark., 2005).

Bu bağlamda, fen derslerinde eğitim teknolojisinin öğrencilere sunduğu imkânlardan yararlanılması ve bu etkilerin derinlemesine incelenmesi büyük önem arz etmektedir. Eğitim teknolojilerinin fen derslerinde kullanıma yönelik öğretmen, öğretmen adayları ve yöneticilerin görüşlerinin belirlenmesi üzerine alanda çokça çalışmayla karşılaşılmaktadır. İlgili literatür incelendiğinde, İnel, Evrekli ve Balım'ın (2011), çalışmasında fen ve teknoloji dersinde eğitim teknolojilerinin kullanılmasına ilişkin öğretmen adaylarının görüşlerini belirlemeye yönelik, Kaya ve Tarkın-Çelikkıran'ın (2020) çalışmasında kimya öğretiminde öğretim teknolojilerinin kullanımına yönelik öğretmen görüşlerinin incelenmesine yönelik, Erdem (2018) ise liselerdeki fizik eğitiminde teknolojinin kullanılmasına yönelik öğretmen görüşlerini inceledikleri görülmektedir. Ayrıca Erdem ve Uzal (2018) liselerde fizik eğitimini iyileştirme yönünde teknolojinin kullanılmasına yönelik yönetici görüşleri üzerine çalışmalar gerçekleştirmişlerdir. Ancak öğrencilere yönelik çalışmaların oldukça kısıtlı olduğu görülmektedir. Dolayısıyla eğitimin merkezinde olan öğrencilerin konu hakkındaki görüşleri de oldukça önemlidir ve alanda, fen derslerinde teknoloji kullanımına yönelik öğrenci görüşlerinin incelenmesi üzerine 
çalışmalar yapılması gerektiği anlaşılmaktadır. Literatürde fizik, kimya ve biyoloji branşları için ayrı ve güncel çalışmalara rastlanmadığından dolayı bu araştırmada ortaöğretim öğrencilerinin, liselerdeki fen eğitiminde teknolojinin kullanılmasına yönelik görüşlerini çeşitli değişkenler açısından incelenmesi amaçlanmıştır. Bu amaç doğrultusunda aşağıdaki sorulara cevap aranmıştır:

1. Ortaöğretim öğrencilerinin lisedeki fen (fizik, kimya, biyoloji) eğitiminde teknoloji kullanımına yönelik görüşlerinin düzeyi nedir?

2. Ortaöğretim öğrencilerinin liselerdeki fen eğitiminde teknoloji kullanılmasına yönelik görüşleri demografik özelliklere (cinsiyet, sınıf düzeyi, okul türü, öğrenim gördüğü kurum) göre farklılaşmakta mıdır?

3. Ortaöğretim öğrencilerinin liselerdeki fen eğitiminde teknoloji kullanılmasına yönelik görüşleri ölçeğin yanıtlandığı fen dersine (fizik, kimya ve biyoloji) göre farklılaşmakta midir?

\section{Yöntem}

\section{Araştırmanın Modeli}

Ortaöğretim öğrencilerinin liselerdeki fen eğitiminde teknolojinin kullanılmasına yönelik görüşlerinin belirlenmesinin amaçlandığı bu çalışma için nicel araştırma yöntemlerinden ilişkisel tarama modeli seçilmiştir. İlişkisel tarama modeli, incelenen çeşitli değişkenler arasındaki ilişkinin varlığını ve hangi derecede olduğunu belirlemeyi amaçlayan araştırma modelleridir. Karşılaştırma türünde yapılan ilişkisel tarama modellerinde ise incelenen değişken, bağımsız değişkenin alt gruplarına göre kıyaslanarak aralarında bir farklılaşma olup olmadığı araştırılmaktadır. Bu sayede bağımsız değişken ile bağımlı değişken arasındaki ilişkiler açığa çıkartılmaktadır (Karasar. 1999). Dolayısı ile bu çalışmada öğrencilerin tutum düzeylerinin ortaya konmasının yanında, incelenen demografik gruplar ile katılımcılara yöneltilen sorulara verilen cevapların oluşturduğu gruplar 1şı̆̆ında fen bilgisine yönelik tutumların dağılımları derinlemesine incelenmiş ve tutuma etki eden faktörler açığa çıkartılmaya çalışılmıştır.

\section{Örneklem}

Araştırmanın evrenini 2020-2021 eğitim öğretim güz yarıyılında Doğu Anadolu Bölgesindeki illerde öğrenim görmekte olan ortaöğretim öğrencileri oluşturmaktadır. Araştırmanın örneklem grubunu ise Doğu Anadolu bölgesinin farklı illerinde, 2020-2021 eğitim-öğretim yılında öğrenim gören 199 ortaöğretim öğrencisi oluşturmaktadır. 
Araştırmacının Doğu Anadolu Bölgesinde bulunan bir lisede görev yapan bir öğretmen olmasından dolayı, bu bölgede bulunan liselerde öğrenim görmekte olan ortaöğretim öğrencilerine ulaşmasının hızlı ve kolay olabileceği göz önünde bulundurularak, nicel araştırma için seçkisiz olmayan örnekleme yöntemlerinden kolay ulaşılabilir durum örneklemesi kullanılmıştır. Kolay ulaşılabilir durum örneklemesi, çalışmayı hızlı ve pratik bir şekilde yürütmeyi sağlayan, araştırmacının kendisine yakın ve erişilmesi kolay olan bir durumu seçtiği örneklemedir (Patton, 1987).

\section{Veri Toplama Araçları}

Çalışmanın verilerine ulaşmak için Erdem ve Uzal (2018) tarafından geliştirilen ve diğer fen dersleri kullanımına da uygun olduğu belirtilen 1.faktör altında 10, 2. faktör altında ise 4 olmak üzere toplam 14 maddeden oluşan beşli Likert tipinde "Teknolojinin Fizik Eğitiminde Kullanımına Yönelik Öğrenci Görüş Ölçeği” kullanılmıştır. Erdem ve Uzal'ın yürüttükleri çalışmada ölçeğin iç tutarlılığını belirlemek için Cronbach Alpha katsayıları hesaplanmış olup; birinci alt boyut için 0.86 , ikinci alt boyut için 0.78 ve tüm ölçek için 0.89 olarak bulunmuştur. Elde edilen bulgular doğrultusunda hazırlanan ölçeğin; lise öğrencilerinin fen eğitiminde teknoloji kullanımına yönelik görüşlerinin saptanmasında kullanılabilmek üzere geçerli ve güvenilir bir araç olduğu anlaşılmaktadır.

Ölçek formu, Google Formlar yardımıyla bilgisayar ortamına aktarılmıştır. Ayrıca katılımcıların demografik özellikleriyle ilgili bilgiler edinebilmek için ölçeğe demografik bilgiler kısmı eklenmiş ve ölçeğin yanıtlanacağı fen dersinin ne olduğunun tespiti için bu demografik sorular içeresinde “ölçeğin hakkında yanıtlanacağı fen dersi nedir” maddesi eklenmiştir. Katılımcılara WhatsApp ve Messenger gibi sosyal medya iletişim araçları üzerinden ulaşılarak ölçek formunun doldurulması sağlanmıştır.

\section{Verilerin Analizi}

$\mathrm{Bu}$ çalışmada toplanan veriler betimsel ve yordamalı istatistik teknikleri kullanılarak $\% 5$ anlamlılık düzeyinde analiz edilmiştir. Verilerin analizi SPSS 18 Veri Analiz programında yapılmıştır. Yordamalı istatistiklerde verilerin normal dağılıp dağılmadığına bakmak için Kolmogorov-Smirnov ile Shapiro-Wilk normallik testleri kullanılmıştır. Ayrıca verilerin alt gruplara dağılımları yüzdelik dilimler halinde sunulmuş ve bu gruplara ilişkin aritmetik ortalama ve standart sapma değerleri ile çalışmanın güvenirliğine katkı sağlaması amacıyla standart hata değerleri sunulmuştur. Diğer taraftan cinsiyet, okul türü, sınıf düzeyi, öğrenim görülen kurum ve ölçeğin yanıtlandığı ders faktörlerinin fen eğitiminde teknoloji kullanılmasına yönelik öğrenci görüşlerine etkilerinin araştırılması amacıyla ilişkisiz ölçümler 
YYÜ Eğitim Fakültesi Dergisi (YYU Journal of Education Faculty), 2021; 18(1)933-949,http://efdergi.yyu.edu.tr,

için parametrik olmayan testlerden Mann Whitney U-Testi ve Kruskal Wallis Testleri uygulanmıştır.

\section{Bulgular}

\section{Betimsel İstatistikler}

$\mathrm{Bu}$ bölümde ortaöğretim öğrencilerinin demografik gruplara dağılımları, gruplara ilişkin ortalama ve standart sapma değerleri ile ölçeğin yanıtlandığı ders ve ölçek maddelerine verilen yanıtlar hakkındaki frekans dağılımlarına yer verilmiştir.

Tablo 1. Demografik Bilgiler ve Ölçeğin Yanıtlandı̆̆ı Ders Hakkındaki Betimsel İstatistikler

\begin{tabular}{|c|c|c|c|c|c|c|}
\hline Faktör & Grup & $\mathbf{N}$ & $\%$ & Ort. & Stn. Sap. & Stn. Hata \\
\hline \multirow{2}{*}{ Cinsiyet } & Erkek & 132 & $66,0 \%$ & 54,45 & 12,15 & 1,07 \\
\hline & Kız & 68 & $34,0 \%$ & 55,43 & 10,25 & 1,24 \\
\hline \multirow{4}{*}{ Sinıf Düzeyi } & 9. Sinıf & 118 & $60,5 \%$ & 54,28 & 12,38 & 1,14 \\
\hline & 10. Sinif & 18 & $9,2 \%$ & 55,50 & 12,12 & 2,86 \\
\hline & 11. Sinif & 10 & $5,1 \%$ & 55,10 & 10,05 & 3,18 \\
\hline & 12. Sinıf & 49 & $25,1 \%$ & 56,04 & 9,83 & 1,42 \\
\hline \multirow{4}{*}{ Okul Türü } & Anadolu Lisesi & 47 & $24,0 \%$ & 55,66 & 10,37 & 1,51 \\
\hline & Anadolu İmam Hatip Lisesi & 14 & $7,1 \%$ & 46,07 & 19,46 & 5,20 \\
\hline & Fen Lisesi & 15 & $7,7 \%$ & 54,20 & 10,97 & 2,83 \\
\hline & $\begin{array}{l}\text { Mesleki ve Teknik Anadolu } \\
\text { Lisesi }\end{array}$ & 118 & $60,2 \%$ & 55,55 & 10,62 & ,99 \\
\hline \multirow{2}{*}{$\begin{array}{l}\text { Öğrenim Görülen } \\
\text { Kurum }\end{array}$} & Devlet Okulu & 71 & $36,2 \%$ & 53,31 & 13,27 & 1,59 \\
\hline & Özel Okul & 125 & $63,8 \%$ & 55,60 & 10,54 & ,95 \\
\hline \multirow{3}{*}{$\begin{array}{l}\text { Ölçeğin Hakkında } \\
\text { Yanıtlandığı Ders }\end{array}$} & Biyoloji & 86 & $44,3 \%$ & 56,95 & 8,25 & ,90 \\
\hline & Fizik & 68 & $35,1 \%$ & 52,87 & 14,34 & 1,74 \\
\hline & Kimya & 40 & $20,6 \%$ & 54,64 & 10,22 & 1,64 \\
\hline Toplam & & 199 & $\% 100$ & 54,78 & 11,48 & 0,81 \\
\hline
\end{tabular}

Tablo 1'e göre katılımcılar cinsiyet değişkeni açısında incelendiğinde, erkek katılımcıların ortalaması 54,45 iken kız katılımcıların ortalaması ise 55,43 olarak bulunmuştur. Dolayısı ile cinsiyet grupları açısından ortalamaların oldukça yakın olduğu görülmektedir. Yine Tablo 1'e göre katılımcılar sınıf düzeyi değişkeni açısından incelendiğinde, 12. Sınıfların 56.04 ortalama ile en yüksek puana sahip oldukları görülmektedir. Daha sonra 10. ve 11. Sınıfların ortalamalarının birbirine oldukça yakın olduğu, en düşük ise 9.sınıfların başarı gösterdiği görülmektedir. Diğer taraftan okul türü değişkeni incelendiğinde ise, 47 tane Anadolu Lisesi katılımcısının ortalamasının 55.66 iken, 14 tane Anadolu İmam Hatip Lisesi katılımcısının ortalamasının 46.07 iken 118 tane Mesleki ve Teknik Anadolu Lisesi katılımcısının ortalamasının 55.55 olduğu görülmüştür. Son olarak 15 tane Fen Lisesi katılımcısının ortalamasının 54.20 puan olduğu görülmektedir. Öğrenim görülen kurum değişkeni olarak ele alındığında ise Tablo 1'deki verilere göre devlet okulu katılımcısının ortalamasının 53.31 iken özel okul katılımcısının ortalamasının 55 olduğunu göstermektedir. Son olarak ölçeğin yanıtlandığı ders değişkeni incelendiğinde, Biyoloji branşında ölçeği cevaplandırılmasında 
ortalamanın 56.95 iken Fizik branşında ölçeğin ortalamasının 52.87 olduğu, Kimya branşında ise ortalamanın 54.64 puan olduğu görülmektedir. Ölçek puanlarına yönelik ortalamaların haricinde öğrencilerinin ölçek maddelerine verdikleri cevaplara ait yüzdelik dağılımlar Tablo 2'de sunulmuştur. Tablo üst satırında "Kesinlikle Katılmıyorum” yanıtları "1", "Katılmıyorum" yanıtları "2", "Kararsızım” yanıtları “3”, "Kat1lıyorum” yanıtları “4”, "Kesinlikle Katıliyorum” yanıtları "5" numara ile gösterilmiştir.

Tablo 2. Ölçek Maddelerine Verilen Yanıtlara ait yüzdelik dağılımlar.

\begin{tabular}{|c|c|c|c|c|c|c|}
\hline No & Maddeler & 1 & 2 & 3 & 4 & 5 \\
\hline 1 & Laboratuvarda yapılamayan deneylerin anlaşılmasına katkısı olur & 6,1 & 8,2 & 26,0 & 20,4 & 39,3 \\
\hline 2 & Teknoloji kullanımı öğrenme ortamını zenginleştirir & 1,0 & 6,5 & 15,6 & 25,1 & 51,8 \\
\hline 3 & Teknoloji kullanımı hayal gücümü geliştirir & 4,5 & 7,5 & 24,1 & 24,6 & 39,2 \\
\hline 4 & Yaratıcı düşünme becerilerimi geliştirmede yardımcıdır & 1,0 & 6,6 & 21,2 & 25,8 & 45,5 \\
\hline 5 & Konuları öğrenmede ilgimi arttırır & 5,5 & 8,0 & 16,1 & 23,6 & 46,7 \\
\hline 6 & Öğrenmeye daha çok güdüler (isteklendirir) & 3,5 & 5,5 & 24,6 & 23,6 & 42,7 \\
\hline 7 & Teknoloji kullanımı takım çalışması becerilerimi geliştirir & 7,2 & 10,3 & 30,3 & 18,5 & 33,8 \\
\hline 8 & Bilimsel düşünme becerilerimi geliştirmeme katkısı olur & 3,6 & 10,3 & 18,0 & 28,4 & 39,7 \\
\hline 9 & Öğrenme etkinliklerine katılım olanaklarını arttırır & 2,6 & 5,7 & 23,7 & 21,6 & 46,4 \\
\hline 10 & Teknolojinin derslerde daha sık kullanılmasını isterim & 2,6 & 9,3 & 19,6 & 21,1 & 47,4 \\
\hline 11 & Konu içeriğini kolaylıkla anlamama yardımcı olur & 2,6 & 5,2 & 23,2 & 27,3 & 41,8 \\
\hline 12 & Konuları kısa sürede öğrenmeme olumlu etkisi vardır & 3,1 & 7,2 & 22,7 & 27,8 & 39,2 \\
\hline 13 & Bilgiye hızlı erişmemde çeşitli olanaklar sağlar & 1,0 & 2,1 & 15,5 & 19,6 & 61,9 \\
\hline 14 & Birden çok duyu organıma hitap eder & 2,1 & 8,8 & 27,5 & 20,7 & 40,9 \\
\hline
\end{tabular}

Katılımcıların ölçekten aldıkları toplam puanlar göz önünde bulundurulduğunda ortalama puanın 54,79 olduğu görülmüştür. Dolayısı ile öğrencilerin ölçekten \%78,27 oranında başarılı olduğu sonucuna ulaşılmıştır.

Diğer taraftan Tablo 2'deki verilere göre, katılımcıların ölçek maddelerinin her birine verdikleri yanıtların çoğunluğunun “Tamamen Katılıyorum” seçeneğinde olduğunu ve ardından bu yanıtı "Katılıyorum” seçeneğinin takip ettiğini, yanıt olarak en az tercih edilen seçeneğin ise “Kesinlikle Katılmıyorum” olduğunu söylemek mümkündür. Örneğin, “Teknoloji kullanımı öğrenme ortamını zenginleştirir” maddesine 103 (\%51.8) öğrenci “Tamamen Katılıyorum” derken, 50 (\%25.1) öğrenci “Katılıyorum” yanıtını vermiş, 2 (\%1) öğrenci ise “Kesinlikle Katılmıyorum” seçeneğini işaretlemiştir.

\section{Yordamalı İstatistikler}

Bu bölümde ortaöğretim öğrencilerinin liselerde fen eğitiminde teknoloji kullanılmasına yönelik görüşlerinin demografik özelliklere ve fen (fizik, kimya, biyoloji) derslerine göre farklılık gösterip göstermediği ile ilgili bulgulara yer verilmiştir. Ölçek puan dağılımının değişkenlere göre normal dağılıma uygun olup olmadığına bakmak amaciyla KolmogorovSmirnov ve Shapiro-Wilk testleri uygulanmıştır. Tablo 3'te ölçek puanlarının, cinsiyet, sınıf 
düzeyi, okul türü, öğrenim görülen kurum ve ölçeğin yanıtlandığı derse göre oluşan alt gruplara yönelik yapılan normallik testi sonuçları sunulmuştur.

Tablo 3. Ölçek Puanlarının Değişkenlere Göre Normallik Testi Sonuçları

\begin{tabular}{|c|c|c|c|c|c|c|c|}
\hline \multirow{2}{*}{ Faktör } & \multirow{2}{*}{ Grup } & \multicolumn{3}{|c|}{ Kolmogorov-Smirnov } & \multicolumn{2}{|c|}{ Shapiro-Wilk } & \multirow[b]{2}{*}{ Sd. } \\
\hline & & İst. & Sd. & Sig. & Statistic & İst. & \\
\hline \multirow{2}{*}{ Cinsiyet } & Erkek & ,115 & 121 &, 000 & ,897 & 121 &, 000 \\
\hline & $\mathrm{K}_{1 \mathrm{Z}}$ & 087 & 62 & 200 & ,945 & 62 & ,008 \\
\hline \multirow{4}{*}{ Sınıf Düzeyi } & 9. Sinıf & ,116 & 109 & ,001 & ,899 & 109 &, 000 \\
\hline & 10. Sinif & ,171 & 17 & 200 & ,903 & 17 &, 076 \\
\hline & 11. Sinif & ,187 & 10 & ,200 & ,921 & 10 & ,365 \\
\hline & 12. Sinif & 154 & 47 & 007 & ,927 & 47 &, 006 \\
\hline \multirow{4}{*}{ Okul Türü } & Anadolu Lisesi & ,117 & 47 & 110 & 946 & 47 & 031 \\
\hline & Anadolu İmam Hatip Lisesi & ,333 & 13 & 000 & ,762 & 13 & ,003 \\
\hline & Fen Lisesi &, 140 & 13 & 200 & ,951 & 13 & ,615 \\
\hline & Mesleki ve Teknik Anadolu Lisesi & 107 & 108 & 004 & ,951 & 108 &, 001 \\
\hline \multirow{2}{*}{$\begin{array}{l}\text { Öğrenim } \\
\text { Kurumu }\end{array}$} & Devlet Okulu & ,148 & 68 & 001 & ,890 & 68 &, 000 \\
\hline & Özel Okul & 105 & 115 & ,003 & ,947 & 115 &, 000 \\
\hline \multirow{3}{*}{$\begin{array}{l}\text { Ölçeğin } \\
\text { Yanıtlandığ1 } \\
\text { Ders }\end{array}$} & Biyoloji & ,083 & 84 & ,200 & ,960 & 84 & ,010 \\
\hline & Fizik & ,121 & 64 & ,020 & ,904 & 64 &, 000 \\
\hline & Kimya & 093 & 35 & ,200 & ,953 & 35 & ,139 \\
\hline
\end{tabular}

Tablo 3'e göre, cinsiyet değişkeni açısından erkeklerin ölçek puan dağılımının normal dağılıma uygun olmadığı ( $\mathrm{p}=.00$ ), kızların ölçek puan dağılımının ise normal dağılıma uygun olduğu ( $p=.20)$ görülmektedir. Sınıf düzeyi değişkeni açısından bakıldığında ise 9. ve 12 . sınıfların ölçek puan dağılımlarının normal dağılıma uygun olmadığı $(p<.05), 10$. ve 11 . sınıfların ölçek puan dağılımlarının ise normal dağılıma uygun olduğu (p>.05) anlaşılmaktadır. Diğer taraftan okul türü değişkeni açısından bakıldığında, Anadolu İmam Hatip Lisesi ve Mesleki ve Teknik Anadolu Lisesi ölçek puan dağılımlarının normal dağılıma uygun olmadığı $(p<.05)$, Anadolu Lisesi ve Fen Lisesi ölçek puan dağılımlarının ise normal dağılıma uygun olduğu (p>.05) görülmüştür. Öğrenim kurumu değişkeni açısından sonuçlar incelendiğinde ise hem Devlet Okulu hem de Özel Okul ölçek puan dağılımlarının normal dağılıma uygun olmadığı görülmektedir $(\mathrm{p}<.05)$. Son olarak ölçeğin yanıtlandığı ders değişkeni açısından, Fizik branşı ölçek puan dağılımının normal dağılımına uygun olmadığı $(\mathrm{p}<.05)$, Biyoloji ve Kimya branşları ölçek puan dağılımlarının ise normal dağılıma uygun olduğu ( $p>.05$ ) bulunmuştur. Buna göre cinsiyet, sınıf düzeyi, okul türü, öğrenim görülen kurum ve ölçeğin hakkında yanıtlandığı ders değişkenleri açısından ayrı ayrı Tablo 3 incelendiğinde, ölçek puan dağılımlarının değişkenlerin alt gruplarının tümünde normal dağılmadığı görülmüştür. $\mathrm{Bu}$ nedenle iki alt grup barındıran değişkenler için parametrik olmayan bir test olan ilişkisiz ölçümler için Mann Whitney U-Testi kullanılmış, üç alt grup ve daha olanlar için parametrik olmayan bir test olan Kruskal Wallis H Testi uygulanmıştır. Analizler eksik veriler göz ardı 
edilerek geçerli veriler üzerinden gerçekleştirilmiştir. Ölçek puanının cinsiyet ve okul türüne göre Mann Whitney U-Testi ile kıyaslanmasına ilişkin sonuçlar Tablo 4’te sunulmuştur.

Tablo 4. Ölçek Puanlarının Cinsiyet ve Okul Türüne Göre Kıyaslanmasına Yönelik Gerçekleştirilen Mann Whitney U-Testi Sonuçları

\begin{tabular}{|c|c|c|c|c|c|c|c|c|}
\hline Faktör & Gruplar & $\mathbf{N}$ & Med. & Rank.Ort. & Rank top. & $\mathbf{U}$ & $\mathbf{Z}$ & p \\
\hline \multirow{2}{*}{ Cinsiyet } & Erkek & 130 & 57 & 98,95 & 12863,5 & \multirow{2}{*}{ 4348,5 } & \multirow{2}{*}{,- 187} & \multirow{2}{*}{,852* } \\
\hline & $\overline{\mathrm{K}} \mathrm{zz}$ & 68 & 56 & 100,55 & $\begin{array}{l}6837,5 \\
\end{array}$ & & & \\
\hline Öğrenim & Devlet Okulu & 70 & 56 & 92,64 & 6485 & 4000 &,- 906 & ,365* \\
\hline Kurumu & Özel Okul & 124 & 57,5 & 100,24 & 12430 & 4000 & -,900 & ה"305, \\
\hline
\end{tabular}

*p>.05 anlamlı farklılık bulunmamakta

Mann-Whitney testi sonuçlarına göre, toplam ölçek puanı değişkeni açısından erkek grubu $(\mathrm{Mdn}=57)$ ile k1z grubu $(\mathrm{Mdn}=56)$ arasında istatiksel olarak anlamlı bir farklılık bulunmamaktadır, (U=4348.5, p=.852). Aynı şekilde Mann-Whitney $U$ testi sonuçlarına göre, toplam ölçek puanı değişkeni açısından devlet okulu grubu (Mdn=56) ile özel okul grubu $(\mathrm{Mdn}=57.5)$ arasında istatiksel olarak anlamlı bir farklılık bulunmamaktadır, $(\mathrm{U}=4000$, $\mathrm{p}=.365$ ). Diğer taraftan ölçek puanının sınıf düzeyine göre Kruskal Wallis Testi ile kıyaslanması sonuçları Tablo 5 'te sunulmuştur.

Tablo 5. Ölçek Puanının Sınıf Düzeyine Göre Kıyaslanmasına Yönelik Gerçekleştirilen Kruskal Wallis Testi Sonuçları

\begin{tabular}{lllllll}
\hline Sinıf Düzeyi & $\mathbf{N}$ & Med & Rank Ort & $\chi^{2}$ & Sd & p \\
\hline 9. Sinıf & 117 & 57 & 95,34 &, 374 & 3 &, $946^{*}$ \\
\hline 10. Sinıf & 18 & 59 & 99,39 & & & \\
\hline 11. Sinıf & 10 & 57,5 & 94,25 & & & \\
\hline 12. Sinıf & 48 & 56 & 100,72 & & & \\
\hline
\end{tabular}

*p>.05 anlamlı farkl11ık bulunmamakta

Kruskal Wallis testi sonuçlarına göre, toplam ölçek puanı değişkeni açısından sınıf düzeyi değişkeninde gruplar arası anlamlı bir fark bulunmamaktadır ( $p=.946)$. Ölçek puanının okul türüne göre Kruskal Wallis H Testi ile kıyaslanmasına ilişkin sonuçlar ise Tablo 6'da sunulmuştur.

Tablo 6. Ölçek Puanının Okul Türüne Göre Kıyaslanmasına Yönelik Gerçekleştirilen Kruskal Wallis Testi ile kıyaslanması Sonuçları

\begin{tabular}{lllllll}
\hline Okul Türü & $\mathbf{N}$ & Med & Rank Ort & $\boldsymbol{\chi 2}^{\mathbf{2}}$ & Sd & p \\
\hline Anadolu Lisesi & 47 & 56 & 99,50 & 4,936 & 3 &, $424^{*}$ \\
\hline Anadolu İmam Hatip Lisesi & 14 & 51 & 72,93 & & & \\
\hline Fen Lisesi & 15 & 52 & 92,13 & & & \\
\hline Mesleki ve Teknik Anadolu Lisesi & 116 & 57 & 99,91 & & & \\
\hline
\end{tabular}

${ }^{*} \mathrm{p}>.05$ anlamlı farklılık bulunmamakta

Kruskal Wallis H testi sonuçlarına göre, toplam ölçek puanı değişkeni açısından okul türü değişkeninde gruplar arası anlamlı bir fark bulunmadığı görülmektedir ( $p=.424)$. Diğer 
taraftan ölçek puanının ölçeğin yanıtlandığı derse göre kıyaslanması amacıyla gerçekleştirilen Kruskal Wallis H Testi sonuçları Tablo 7'de sunulmuştur.

Tablo 7. Ölçek Puanının Ölçeğin Yanıtlandı̆̆ı Derse Göre Kıyaslanmasına Yönelik Gerçekleştirilen Kruskal Wallis Testi Sonuçları

\begin{tabular}{lcclccc}
\hline Ölçeğin Yanıtlandığı Ders & $\mathbf{N}$ & Med & Rank Ort & $\chi^{\mathbf{2}}$ & Sd & p \\
\hline Biyoloji & 85 & 58 & 103,38 & 2,358 & 2 &, $308^{*}$ \\
\hline Fizik & 68 & 56 & 90,54 & & & \\
\hline Kimya & 39 & 55 & 91,90 & & & \\
\hline
\end{tabular}

*p>.05 anlamlı farklılık bulunmamakta

Kruskal Wallis testi sonuçlarına göre, toplam ölçek puanı değişkeni açısından ölçeğin yanıtlandığı ders değişkeninde gruplar arası anlamlı bir fark bulunmadığı görülmektedir $(\mathrm{p}=.308)$.

\section{Sonuç, Tartışma ve Öneriler}

Amacı teknolojinin fen eğitimde kullanılmasına yönelik ortaöğretim öğrencilerinin görüşlerinin incelenmesi olan bu çalışma 199 ortaöğretim öğrencisinin [132 (\% 66)'s1 erkek, 68 (\% 34)'ü kı] katılımı ile gerçekleştirilmiştir. Araştırmada ortaöğretim öğrencilerinin lisedeki fen (fizik, kimya, biyoloji) eğitiminde teknoloji kullanımına yönelik görüşlerinin düzeyini belirlemek için ölçek maddelerine verilen yanıtlar analiz edilmiş ve öğrencilerin ölçekten \%78 oranında başarı gösterdikleri sonucuna ulaşılmıştır. Bu sonuç katılımcıların teknolojinin fen eğitiminde kullanımına yönelik olumlu görüş bildirdikleri şeklinde yorumlanabilmektedir. Katılımcıların çoğunluğu ölçek maddelerine “Tamamen Katılıyorum” yanıtını verirken, bunu takip eden ve en çok tercih edilen diğer seçenek ise "Katılıyorum" yanıtı olmuştur.

Ayrıca ölçek maddelerine verilen yanıtlar detaylı incelendiğinde ise "Bilgiye hızlı erişmemde çeşitli olanaklar sağlar" maddesine verilen yanıtlarda "Katılıyorum" ve üzeri yanıt verenlerin \%82.5 oranında oldukları görülmektedir. Benzer şekilde "Teknoloji kullanımı öğrenme ortamını zenginleştirir” maddesi incelendiğinde ise öğrenciler \%51.8 oranında "Kesinlikle katılıyorum" şeklinde yanıtlarken \%25.1 oranında ise "Katılıyorum" yanıtını vermiş̧lerdir. Dolayısı bu durum öğrencilerin fen derslerinde teknolojinin kullanılmasına genel olarak istekli olduklarını ve teknoloji kullanımını desteklediklerini göstermektedir. Diğer taraftan tüm maddeler içerisinde en çok olumsuz yanıt verilen madde ise "Teknoloji kullanımı takım çalışması becerilerimi geliştirir” olmuştur. Bu maddeye verilen yanıtların \% 7.2 oranında “Kesinlikle katılmıyorum” yanıtı verilmiştir. Bu oranın diğer maddelerde $\% 2$ civarında olduğu görülmektedir. 
Araştırmada öğrencilerin tutumlarına etki eden çeşitli faktörler incelenmiştir. Elde edilen diğer bulgulara göre, ortaöğretim öğrencilerinin liselerdeki fen eğitiminde teknolojinin kullanımına yönelik görüşlerine cinsiyetin herhangi bir anlamlı etkisinin bulunmadığı sonucuna ulaşılmıştır. Buna göre kız ve erkek öğrenciler arasında tutum açısından bir farklılık olmadığı görülmüştür. Diğer taraftan sınıf düzeyi, okul türü, öğrenim görülen kurum ve ölçeğin yanıtlandığı fen dersi de incelenmiştir. Bu faktörlerinde öğrencilerin tutumlarına olumlu veya olumsuz herhangi bir etkisinin olmadığı anlaşılmaktadır. Bu sonuç cinsiyet, sınıf düzey, okul türü, öğrenim görülen kurum ve fen derslerinin branşı fark etmeksizin öğrencilerin fen eğitimine teknolojinin entegre edilmesini istedikleri şeklinde yorumlanabilir. Elde edilen bu sonuç literatürde yer alan diğer çalışmalarla benzerlik göstermektedir. Akpınar ve ark. (2005), öğrencilerin eğitim teknolojisinin derslerde kullanılmasının başarılarına olumlu katkısı olacağını düşündüklerini raporlamışlardır. Benzer sonuçlar Önal, N. (2014) ve Önal, T. (2017) tarafindan da raporlanmıştır.

Araştırmadan çıkan sonuçlara göre, öğrencilerin bu konuyu destekledikleri ve bu durumunda başarıyı arttırıcı bir unsur olduğu göz önünde bulundurularak, fen derslerinde teknolojinin daha çok sıklıkla kullanılması, liselerde eğitim teknolojisi araç-gereç imkânlarının arttırılması ve gerek okul binasının gerek ders içeriklerinin her türlü teknolojik araç-gereçle donatılması önerilmektedir. Benzer bir öneri 2005 yılında Akpınar ve ark. tarafindan da yapılmıştır.

$\mathrm{Bu}$ çalışma Fizik, Kimya ve Biyoloji dersleri için aynı anda gerçekleştirilmiş bir çalışmadır. Katılımcıların çoğunluğunun teknolojinin bu derslerde kullanılmasını destekledikleri sonucuna ulaşılsa bile bazı katılımcılar teknoloji kullanımı yönünde olumsuz görüş bildirmişlerdir. Bu görüşü bildirmelerindeki etki kaynaklarına ulaşabilmek adına bir çalışma yürütülebilir. Her branş için farklı nedenler ortaya çıkabilir, ya da öğrencinin bu görüşü bildirmesindeki sebep o branştaki belirli konular için teknolojinin kullanılmasını uygun bulmamasından kaynaklanmış olabilir. Bu gibi sebeplerden ötürü ortaya çıkabilecek olumsuz görüşlerin nedenini ortaya çıkarmak ve çözmek için tek bir branşa ya da o branştaki belirli konular üzerine teknolojinin kullanımına yönelik öğrenci görüşlerini tespit etmek adına farklı çalışmaların yürütülmesi önerilmektedir.

\section{Makalenin Bilimdeki Konumu}


YYÜ Eğitim Fakültesi Dergisi (YYU Journal of Education Faculty), 2021; 18(1)933-949,http://efdergi.yyu.edu.tr,

Matematik ve Fen Bilimleri Eğitimi/ Fen Bilgisi Eğitimi

\section{Makalenin Bilimdeki Özgünlüğ̈̈}

Alan yazında eğitim teknolojisi araç-gereçlerinin fen bilgisi derslerinde daha çok kullanılması, okullarda eğitim teknolojisi araç-gereç imkanları arttırılması ve her türlü teknolojik araç-gereçle donatılmasına yönelik pek çok vurgu yapıldığı görülmektedir. Günümüzde gelinen noktada artan imkanlar, yaygınlaşan akıllı telefon ve bilgisayar kullanımı, internete ulaşım gibi imkanlar göz önünde bulundurulduğunda öğrencilerin derste teknoloji kullanımına yönelik görüşlerinin halen olumlu olması ve öğrencilerin bu tür isteklerinin devam etmesi mevcut gelişim yeterli düzeye ulaşmadığını ortaya koymaktadır. Özellikle sanal gerçeklik, artırılmış gerçeklik, yapay zeka gibi günümüz teknolojik imkanlarının okullara ve öğrencilere yeterince ulaşmadığ d düşünüldüğünde çalışmanın $\mathrm{z}$ kuşağı öğrencilerinin düşüncelerini yansıtması açısından literatüre olumlu katkı sağlayabileceği düşünülmektedir. 


\section{Kaynakça}

Akpınar, E., Aktamış, H. ve Ergin, Ö. (2005). Fen Bilgisi dersinde eğitim teknolojisi kullanılmasına ilişkin öğrenci görüşleri. The Turkish Online Journal of Educational Technology, 4(1), 93-100.

Aykanat, F., Doğru, M. ve Kalender, S. (2005). Bilgisayar destekli kavram haritaları yöntemiyle fen öğretiminin öğrenci başarısına etkisi. Kastamonu Ĕ̆itim Dergisi,13(2), 391-400.

Balım, A. G., Evrekli, E. ve İnel, D. (2011). Öğretmen adaylarının fen ve teknoloji dersinde eğitim teknolojilerinin kullanılmasına ilişkin görüşleri. Kuramsal Eğitimbilim Dergisi, 4(2), 128-150.

Bozkurt, A. (2014). Okul, öğretmen ve kitaplar kadar teknoloji de eğitimde vazgeçilmez olabildi mi? Bilişim Dergisi, 42(170), 50-55.

Çağıltay, K. ve Erdoğmuş, F. U. (2009). Türkiye'de eğitim teknolojileri alanında yapılan master ve doktora tezlerinde genel eğilimler. M. Akgül, E. Derman, U. Çağlayan ve A. Özgit (Ed.), XI. Akademik Bilişim Konferansı Bildirileri (s.389-393) içinde, Şanlıurfa: Harran Üniversitesi.

Çakmak, O. (1999). Fen eğitiminin yeni boyutu: Bilgisayar-multimedya-internet destekli eğitim. Dokuz Eylül Üniversitesi Buca Eğitim Fakültesi Dergisi, 11, 116-125.

Erdem, A. (2018). Liselerdeki fizik eğitiminde teknolojinin kullanılmasına yönelik öğretmen görüşlerinin incelenmesi. Uluslararası Sosyal Araştırmalar Dergisi, 11(56), 505-520.

Erdem, A. ve Uzal, G. (2018). Liselerde fizik eğitimini iyileştirme yönünde teknolojinin kullanılmasına yönelik yönetici görüşleri. Journal of International Social Research, 11(55), 582-592.

Erdem, A. ve Uzal, G. (2018). Ölçek geliştirme çalışması-I: Fizik eğitiminde teknoloji kullanımına yönelik öğrenci görüşleri. Journal of Human Sciences, 15(1), 509-526.

Gökduman, Y. (2017). Teknolojinin eğitimdeki yeri ve önemi. (2017, 26 Mart). Erişim adresi: https://www.ozeldersalani.com/teknolojinin-egitimdeki-yeri-ve-onemi 
YYÜ Eğitim Fakültesi Dergisi (YYU Journal of Education Faculty), 2021; 18(1)933-949,http://efdergi.yyu.edu.tr,

Kaptan, F. ve Korkmaz, H. (2001). Fen eğitiminde proje tabanlı öğrenme yaklaşımı [Projectbased learning aproach in science education]. Hacettepe Üniversitesi Ĕ̌itim Fakültesi Dergisi, 20, 193-200.

Karasar, N. (1999). Bilimsel Araştırma Yöntemi. (9. Basım). Ankara: Nobel Yayın Dağıtım

Kaya, S. ve Tarkın-Çelikkıran, A. (2020). Kimya öğretiminde öğretim teknolojilerinin kullanımına yönelik öğretmen görüşlerinin incelenmesi, Trakya Eğitim Dergisi, 10(3), 897-916.

Önal, N. (2014). Ortaokul matematik öğretmenlerinin eğitimde bilişim teknolojileri kullanımına ilişkin yeterlik ve görüşlerinin araştırılması. Yayınlanmış Doktora Tezi, Gazi Üniversitesi, Eğitim Bilimleri Enstitüsü, Ankara.

Önal, N. T. (2017). Bilgi ve iletişim teknolojileri kullanımı: fen bilgisi öğretmen adaylarının görüşleri. International Journal of Active Learning, 2(1), 1-21.

Patton, M. Q. (1987). How to use qualitative methods in evaluation (No. 4). Sage. 


\section{Summary}

\section{Statement of Problem}

Modern societies are in need of individuals who can access, comprehend, and evaluate information when necessary instead of individuals who memorise it. Therefore, science lessons gain importance the most among the other courses given in this regard (Korkmaz \& Kaptan, 2001). Biology, chemistry, and physics subjects are perceived as classes which are needed to be memorised by students in case living organisms, chemical and physical reactions, and biological basis of life are not taught by experiential learning methods. (Çakmak, 1999). It is known that students have difficulties especially in learning abstract concepts in science lessons and also they could not comprehend these concepts in depth without visualising them (Akpınar, Aktamış, \& Ergin, 2005). For this reason, the use of technology in science education becomes significant in terms of raising individuals that societies need and solving the stated problems. The use of technology in science education is beneficial in two ways; making abstract concepts, which are difficult to visualize in the mind, concrete and providing virtual environments that are difficult or impossible to create in the classroom. In addition, it is seen that it provides adaptation to the learning speed of students, more enjoyable and permanent learning, and display of dangerous experiments in the virtual environment (Aykanat, Doğru, \& Kalender, 2005; Demirci, 2003). Furthermore, students' interest and curiosity in science can be increased by using technology in science lessons and this allows more inventive individuals to be raised (Akpinar et al., 2005).

In this context, it is crucial to benefit from what educational technology offers to students in science lessons and to examine these opportunities in depth. Many studies in the literature have examined the opinions of teachers, teacher candidates and administrators regarding the use of educational technologies in science lessons. However, there are insufficient numbers of studies examining students' opinions. Students are at the center of the education system and their views are important. For this reason, more studies should be carried out in order to examine the students' views about the use of technology in science lessons. The aim of this study is to examine secondary school students' views on the use of technology in high school science education considering various variables, since there are no separate and up-todate studies for physics, chemistry and biology courses in the literature. 


\section{Method}

This study was conducted using the correlational survey model, one of the quantitative research methods. Therefore, this study not only revealed the strength of attitude of the students towards science, but also examined this in depth in different demographic groups and tried to reveal the factors that affect their attitudes. The sample group of the study consists of 199 secondary education students studying in different provinces of the Eastern Anatolia region in the 2020-2021 academic year. In order to obtain the data of the study, the "Student Opinion Scale for the Use of Technology in Physics Education", which was developed by Erdem and Uzal (2018) and suitable for all science subject, was used. The collected data were analyzed at $5 \%$ significance level by using descriptive and inferential statistical techniques.

\section{Findings}

Considering the total scores of participants from the scale, the average score was found 54.79. Therefore, it was concluded that $78.27 \%$ of the students were successful on the scale. In the gender variable analysis, the average score of male participants was found 54.45 , while the average score of female participants was found 55.43. Also, in the grade level variable analysis, it is seen that the 12th graders had the highest score with an average of 56.04. When the school type variable was examined, it was observed that while the average of 47 Anatolian High School participants was 55.66, the average of 14 Anatolian Imam Hatip High School participants was 46.07. In the institution of education variable analysis, it is seen that the average of the public school participant was 53.31, while the average of the private school participant was 55 according to the descriptive analysis results. Finally, when the course variable was examined, it is seen that 56.95 points for the biology course and 54.64 points for the chemistry course and 52.87 points for the physics course.

When the items of the scale were examined in detail, it can be seen that approximately $77 \%$ of the participants responded to the item "Using technology enriches the learning environment” with I agree - Strongly agree options. According to the results of the MannWhitney test in the findings for the analysis of the factor effects, no statistically significant difference was found between the male group and the female group in terms of the total scale score variable. Likewise, it was determined that there was no statistically significant difference between the public school group and the private school group.According to the results of the Kruskal-Wallis test, there was no significant difference between the groups in the grade level 
variable in terms of total scale scores. Similarly, no difference was found in terms of the school type variable and the course variable.

\section{Discussion and Conclusion}

In the study, students' responses given to the scale items were analyzed to measure the strength of secondary school students' attitudes about the use of technology in high school science (physics, chemistry, biology) education, and it was concluded that $78 \%$ of the students achieved the scale. This result can be interpreted as that participants stated a positive opinion regarding the use of technology in science education. The majority of the participants answered with "Strongly agree" to the items of the scale, the second most preferred option following that was "I agree". Other findings obtained from the study suggest that the opinions of secondary school students about the use of technology in science education in high schools do not differ according to gender, grade level, school type, and institution of education. This result can be interpreted as that students support the integration of technology into science education, regardless of gender, grade level, type of school, the institution where they are taught, and the type of science lessons. These results show similarities to other studies in the literature. Akpinar et al. (2002) reported that students think that using educational technology in lessons will contribute to their success in a positive way. Similar results were also reported by Önal, N. (2014) and Önal, T. (2017).

According to the findings of the study, considering that the students support the use of technology in science lessons and this increases their success; technology should be used more frequently in science lessons; opportunities of educational technology equipment use in high schools should be increased; and both the school building and the course content should be equipped with all kinds of technological tools. Similar recommendations were also made in 2002 by Akpinar et al. 